\title{
Study of patient satisfaction with prosthetic treatment
}

\author{
Desislava Dimitrova \\ Department of Pediatric Dentistry, Faculty of Dental \\ Medicine, Medical University - Varna;
}

\begin{abstract}
Subjective assessment of the patient is an important part of each stage of treatment and is decisive for the ultimate success. The purpose of this review is to consider and present the various methods for assessing patient satisfaction with the prosthetic treatment. Accordingly, an electronic search was conducted in the following databases: PubMed, Google, Lilac from December 2017 to September 2018 by keywords. The data obtained are subjected to critical analysis. The most commonly used methods for studying patient satisfaction are through questionnaires that explore the various aspects of function, prophylaxis, aesthetics, human psychics and communication. The evaluation of the answers received is usually done with Likert scale and Visual Analogue Scale. The survey of satisfaction is an excellent method for objectivizing patient expectations and requirements as well as determining the end result of the treatment.
\end{abstract}

Keywords: satisfaction, subjective assessment, patients, prosthetic treatment

\section{Background}

Evaluation of the patient satisfaction is particularly important for the work of each clinician. The data obtained from this type of study can determine the patient's expectations for the attitude and the work of the dental team, the functional, prophylactic and aesthetic requirements for treatment and might enable doctors to achieve higher results in these directions $(1,2)$. Subjective patient assessment is an important part of each stage of treatment and is critical for ultimate success. The questionnaires, methods and indexes for satisfaction assessment explore the various aspects of function, aesthetics, human psyche, communication, etc., in order to obtain representative and reliable results (3). The 
purpose of this review is to analyze and present the various methods for assessing patient satisfaction with the prosthetic treatment. Accordingly, an electronic search was conducted in the following databases: PubMed, Google, Lilac (from December 2017 to September 2018) by keywords: "satisfaction", "subjective assasment", "patients", "prosthetic treatment". The published literature is analyzed, summarized and presented in the main part of this review.

\section{Results}

For a study of the subjective perceptions of the patients with dental care, Davies and Ware (4) create a 19-item questionnaire with rating scale in which patients evaluates 5 key factors that are considered for the most common sources of satisfaction / dissatisfaction - access, location/convenience, price, pain and quality. According to other authors (5), the assessment of patients' satisfaction with dental care should be established by cards whose questions are open to answers. Patient descriptions are rated as "complaint", "praise and complaint", "no comment" and "praise". The sum of the results of all questions represents the ultimate satisfaction of patients from dental care.

Various authors $(6,7,8)$ point to techniques, methods, scales, and questionnaires to investigate the subjective assessment of patients for the provided prosthetic treatment. Of interest is the study of Bakke et al. (9), which aims to establish patient satisfaction after prosthetic restoration over implants. The study is conducted by a person who is not involved in the treatment in order to obtain reliable data and eliminate false positive responses. The questionnaire includes just three questions: "Are you completely satisfied with the function of the new dentures?", "Did the chewing function improve after treatment?", "Is chewing painful?", and the patients have opportunity to respond with "Yes" or "no". Based on the results, the patients are divided into fully satisfied and not fully satisfied.

A commonly used method for examining the subjective assessment of the patients with prosthetic treatment includes "Patient Satisfaction Questionnaire" $(10,11)$. It is usually composed of 19 basic elements that can be modified for the purposes of different studies. The evaluation is done by using the 5point Likert scale developed by Rensis Likert, which includes standard responses corresponding to full consent, consent, neutrality, disagreement, complete disagreement.

In our country in 1989, Anastasov (12) developed a questionnaire and index of satisfaction with overdentures. On every regular checkup, 5 questions, related to the comfort, retention, the possibility of chewing, speaking and the perception of the appearance, are asked to the patients. Each question has four possible answers, each of which corresponds to a 0 to 3 numerical indication. The resulting sum of all questions is divided by 5 and the result represent the satisfaction index.

Dimova $(6,13)$ also develops a targeted questionnaire, the subject of which is the observation of patients' satisfaction with the prosthetic treatment with laboratory and provisionary constructions. The card consists of 9 questions, each of which identifies four possible responses, coinciding with the most common complaints from the patient. The questions are divided into three groups: characterizing the functional value, the prophylactic value and the aesthetic value of the constructions.

Dimova and colleagues $(14,15,16)$ consider the satisfaction of prosthetic treatment with fixed constructions both from the point of view of subjective perception and expectations of the patients, and 
through the prism of objective assessment of dental practitioners for patient satisfaction of their treatment $(17,18)$.

Proposal for the satisfaction study of prosthetic treatment with partial removable dentures in our country is given by Uzunov (19). According to the author, the answers received from questionnaires can be influenced by different factors such as age, education, cultural specifics, etc., and therefore offers two approaches to compiling the cards. In the first one, numerical scales are used - a ten-line line which at the left end shows the least satisfaction, and in the right - the largest. The patient himself ticks one of the digits of the scale expressing his feelings. The second approach is by using the Likert scale with 5 ready answers.

Satisfaction with prosthetic treatment with various types of removable constructions is the subject of a number of scientific developments in Bulgaria. For example, Hadjieva and collegues (20) examine different aspects of subjective assessment of patients regarding their treatment with total dentures. The authors pay attention to the initial conversation with the patient about their complaints and expectations of the upcoming treatment using guiding questions about comfort, function and aesthetics. The results obtained suggest that the extent of the expected improvement "should be discussed and specified before the new treatment is started". Subject of research is also the satisfaction after the completion of the treatment with total dentures of the patients. In the study of Hadjieva and Dimova (21), the objective clinical assessment of dental practitioners regarding the retention and stability of the total dentures is complemented by patients' subjective perception of their overall aesthetic appearance and their ability to chew better with new constructions.

In assessing the satisfaction of the prosthetic treatment of patients with facial and maxillofacial defects, Gerdzhikov (22) examined the quality of life in patients with post-surgical defects. A wider team of scientists $(23,24,25)$ presents scientific information on parameters of patient subjective assessment regarding vitality, social and role emotional functioning, determining their mental health after the prosthetic rehabilitation with an obturator.

\section{Study of satisfaction with prosthetic treatment in childhood}

In pediatric dentistry, the most commonly used questionnaires are Dental Satisfaction Quistionnaire and Dental Visit Satisfaction Scale $(26,27)$, both requiring adaptation when used in different populations and studies.

Rodd and Atkin (28) examine the satisfaction of small patients from removable prosthetic treatment. The authors use a short questionnaire to assess the overall attitude of children to the dentures, the type of the dentures, nutrition, comfort and perception of others. A Visual Analogue Scale is used to evaluate responses. It is a psychometric scale/instrument for measuring subjective sensations or attitudes that cannot be directly measured. Respondents determine their degree of agreement with a statement by indicating a position along a continuous line between two endpoints.

Contemporary researches $(29,30)$ examine patients' satisfaction with the use of crowns. It is assumed (31) that children are the ones that receive the treatment and live with the consequences, which justifies 
the subjective assessment questionnaires being addressed not only to the parents but also to the kids themselves.

Bell et al. (30) indicate that the first stage of satisfaction assessment is the conversation before the interventions between the doctor, the child and his guardian. Open questions are asked about the procedure, appearance, function, and the cost of constructions that determine the important elements of the treatment, according to the child and the parent.

The subjective assessment for treatment with crowns in children is of interest to some scientists (31, 32). For this purpose, the authors use specially developed parent questionnaires which examine overall satisfaction, crown appearance, shape, size, color and endurance. A five-point Likert scale is used to evaluate the received responses. In some of the studies $(33,34)$, parents are given the opportunity to express further impressions of the crowns, as well as to assess the pain and discomfort experienced by their children during the procedure.

Holsinger et al. (35) and Ortorp et al. (36) proposed questionnaires, which are meant to be completed by the parents immediately after cementation of the crowns. Responses are evaluated on the visual analog scale with a division of 0 to $100 \mathrm{~mm}$, with 0 corresponding to extreme discontent and 100 complete satisfaction.

\section{Conclusion}

The patient satisfaction survey is a source of additional information on the achieved results in the three main areas of prosthetic recovery - prophylaxis, function and aesthetics. Inclusion of a satisfaction questionnaire during dental treatment allows the subjective perception and requirements of patients to be objectified, an opportunity to complement the objective assessment of the dental practitioner and to determine the treatment as successful or unsuccessful.

\section{Acknowledgements}

The author expresses his deep gratitude to Associate Professor Mariana Dimova-Gabrovska for the assistance and support provided during the research.

\section{References}

1. Sondell K, Soderfeldt B, Palmqvist S. Dentist-Patient communication and patient satisfaction in Prosthetic Dentistry. Int J Prosthodont 2002; 15(1): 28-37

2. Korchagina $\mathrm{V}$. Methods of increasing the efficiency of restorations of primary teeth in small children. Clinical Dentistry. 2005; 2: 4-9. (in Russian)

3. Dimova M, Peev T. Methodological approach for the study of patient satisfaction with temporary crowns and Bridges. Social Medicine. 2003; 29-30 (in Bulgarian) 
4. Davies A, Ware J. Measuring patient satisfaction with dental care. Soc Sci Med A 1981; 15(6): 751-760

5. Gurdal P, Cankaya H, Onem E, Dincer S, Yilmaz T. Factors of patient satisfaction/dissatisfaction in dental faculty outpatient clinic in Turkey. Community Dent Oral Epidemiol 2000; 28(6): 461-469

6. Dimova, M.: An index of patients' satisfaction after using of provisional restorations in treatment of tooth crown's and dentition restorations -crowns and bridges, Folia medica, Plovdiv, Tomus XXXX, 3A, 1998, 145

7. McLaughlin J, Grindley G, Block G, Winn DM, Preston-Martin S, Schoenberg JB. Dietary factors in oral and pharyngeal cancer. J Natl Cancer Inst 1988; 80(15): 1237-1243

8. Meijer H, Raghoebar G, Van`t Hof M, Geertman M, Van Oort R. Implant-retained mandibular overdentures compared with complete dentures; a 5-years' follow-up study of clinical aspects and patient satisfaction. Clin Oral Implants Res 1999; 10(3): 238-244

9. Bakke M, Holm B, Gotfredsen K. Masticatory Function and Patient satisfaction with ImplantSupported mandibular overdentures: A prospective 5-year study. Int J Prosthodont 2002; 15(6): 575-581

10. Mangelsdorff AD. Patient satisfaction questionnaire. Medical Care 1979; 17(1): 86-90

11. Newsome P, Wright G. A review of patient satisfaction: 2. Dental patient satisfaction: an appraisal of recent literature. Brit Dent J 1999; 186(4): 166-170

12. Anastasov Iv. Treatment of the defects of the dental arches with removable overdentures without retaining element. PhD thesis. Sofia 1989. (in Bulgaria)

13. Dimova M. Preliminary constructions in fixed prosthetic treatment. PhD thesis. Sofia 2003. (in Bulgarian)

14. Dimova M, Peev T. Satisfaction of the patients with prosthetic treatment with laboratory temporary constructions (results of the study). Social medicine. 2003; 1: 430-32. (in Bulgarian)

15. Dimova M, Peev T. Methodological approach for the study of patient satisfaction with temporary crowns and bridges. Social medicine. Sofia. 2003; 1: 29-30. (in Bulgarian)

16. Dimova $\mathrm{M}$, Hadzhieva $\mathrm{H}$. Clinical case of temporary prosthetic treatment with pin-shaped bridge construction in a patient with high social activity. Dentist 21. 2000; 1 (4): 26-27. (in Bulgarian)

17. Dimova, M. Study of the opinion of dental practitioners about the advantages and disadvantages of prosthetic treatment with temporary crowns and bridges. Dental examination. 2001; 83: 18-22. (in Bulgarian)

18. Dimova, M. Sociological study of the knowledge of indications for temporary prosthetic treatment and of the application of three types of temporary constructions - fabric, laboratory and directly made. Problems of dentistry.2001-2002; XXVIII: 10-15(in Bulgarian)

19. Uzunov T. Planning of a prosthetic structure in distal unlimited partial endentulism. PhD thesis. Sofia 2008 (in Bulgarian)

20. Hadzhieva H, Dimova M, Peev T. Clinical procedures contributing to the aesthetic result in total prosthetic treatment. Dental examination.2006; 2: 108-112. (in Bulgarian)

21. Hadzhieva H, Dimova M. Prosthetic treatment in total edentulous patients with expressed uneven atrophy of alveolar bones. Problems of dentistry. 2005; XXXI(II): 33-37. (in Bulgarian)

22. Gerdzhikov I. Quality of life in patients with upper-jaw post-operative defects - analysis and optimization. PhD thesis. Sofia 2015. (in Bulgarian)

23. Gerdzhikov I, Kalachev Y, Dimova M, Apostolov N. Psychological indicators of quality of life in patients treated with obturator - vitality and social functioning. Problems of dentistry. 2015; 41(1): 13-18. (in Bulgarian) 
24. Gerdzhikov I, Dimova M. Study of the quality of life in patients with post-resection dentures of the upper jaw. Social medicine. 2015; 4: 25-26. (in Bulgarian)

25. Gerdzhikov I, Dimova M, Konstantinova D, Arnautska H. Prosthetic rehabilitation in combined maxillo-facial defects. Problems of dentistry. 2016; 42 (1): 11-15. (in Bulgarian)

26. Newsome P, Wright G. A review of patient satisfaction: 2. Dental patient satisfaction: an appraisal of recent literature. Brit Dent J 1999; 186(4): 166-170

27. Corah N, O Shea R. Development of a patient measure of satisfaction with the dentist: The dental visit satisfaction scale. J Behav Med 1984; 7(4): 367-373

28. Rodd $\mathrm{H}$, Atkin J. Denture satisfaction and clinical performance in a paediatric population. Int $\mathrm{J}$ Paediatr Dent 2000; 10(1): 27-37

29. McCormack HM, Horne DJ, Sheather S. Clinical applications of visual analogue scales: a critical review. Psychol Med 1988; 18:1007-19.

30. Bell S, Morgan A, Marshman Z, Rodd H. Child and parental acceptance of performed metal crowns. Eur Arch Paediatr Dent 2010; 11(5): 218-224

31. Leith R, O`Connell, Anne C. A clinical study evaluating success of 2 commercially available preveneered primary molar stainless steel crowns. Pediatr Dent 2011; 33(4): 300-306

32. Shah P, Lee J, Wright J. Clinical success and parental satisfaction with anterior preveneered primary stainless steel crowns. Pediatr Dent 2004; 26(5): 391-395

33. Roberts Ch, Lee J, Timothy Wright J. Clinical evaluation of and parental satisfaction with resinfaced stainless steel crowns. Pediatr Dent 2001; 23(1): 28-31

34. Salami A, Walia T, Bashiri R. Comparison of parental satisfaction with three tooth-colored fullcoronal restorations in primary maxillary incisor. Int J Clin Pediatr Dent 2015; 39(5): 401-406

35. Holsinger D, Wells M, Scarbecz M, Donaldson M. Clinical evaluation and parental satisfaction with pediatric zirconia. Pediatr Dent 2016; 38(3): 192-197

36. Ortorp A, Kihl M, Carlsson G. A 3-year retrospective and clinical follow up study of zirconia single crowns performed in a private practice. J Dent 2009; 37(9): 731-736

\section{Corresponding author:}

Desislava Dimitrova,

Department of Pediatric Dentistry,

Faculty of Dental Medicine,

Medical University - Varna

Email: desislavvva23@gmail.com 